\title{
Clinical presentation and outcome of ectopic pregnancies in a tertiary care rural hospital
}

\author{
Indu Verma ${ }^{1}$, Punya Priya ${ }^{1 *}$, Charvi Chugh ${ }^{1}$, Harsharan Kaur $^{1}$, Dinesh Sood $^{2}$
}

\begin{abstract}
${ }^{1}$ Department of Obstetrics and Gynecology, Maharishi Markandeshwar Institute of Medical Sciences and Research, Mullana, Ambala, Haryana, India

${ }^{2}$ Department of Anaesthesiology, DMC and H, Ludhiana, Punjab, India
\end{abstract}

Received: 29 November 2018

Accepted: 29 December 2018

\author{
*Correspondence: \\ Dr. Punya Priya, \\ E-mail: drinduverma68@gmail.com
}

Copyright: (c) the author(s), publisher and licensee Medip Academy. This is an open-access article distributed under the terms of the Creative Commons Attribution Non-Commercial License, which permits unrestricted non-commercial use, distribution, and reproduction in any medium, provided the original work is properly cited.

\begin{abstract}
Background: Ectopic pregnancy is the commonest cause of the maternal morbidity and mortality in the first trimester of the pregnancy. The aim of this study was to see the clinical presentation, associated risk factors, mode of treatment and outcome.

Methods: Retrospective study conducted in a tertiary care rural hospital. Women with diagnosis of ectopic pregnancy admitted between August 2016 to September 2018 were studied. Medical record files were scrutinized to get the details. Data was analyzed using Microsoft Office Excel (version 2007). Numerical data were subjected to descriptive analysis, with mean \pm standard deviation (SD) and categorical data as frequency and percentage.

Results: Forty cases of ectopic pregnancy were included who were unbooked, non-smokers, married and belonged to rural areas. Eighty percent were in the age group of 20 to 30 years. Maximum were gravida 3 or 4 with commonest presentation was pain, site was tubal. Laparotomy was done in $95 \%$ of women salpingectomy was the commonest surgical procedure done in $32(80 \%)$ women. Salpingoophrectomy was done in one woman and lifesaving hysterectomy in $2(5 \%)$ women for cervical and ruptured interstitial ectopic pregnancy one each. Blood transfusion was required in $28(70 \%)$ women. No mortality was seen.

Conclusions: Women of reproductive age group with pain abdomen and menstrual complaints, even without amenorrhoea, ectopic pregnancy should be ruled out. Treating reproductive tract infections / PID and offering contraceptives will decrease the incidence of ectopic pregnancy. Medical and paramedical staff should do the timely referral to higher centres.
\end{abstract}

Keywords: Ectopic pregnancy, Risk factors, Laparotomy

\section{INTRODUCTION}

Ectopic pregnancy occurs when the blastocyst is implanted anywhere other than the endometrial lining of the uterine cavity with an incidence of $1-2 \%$ of all the pregnancies. ${ }^{1,2}$ It is a life-threatening emergency where the diagnosis can be missed by practitioners causing a serious hazard to a woman's health and reproductive potential, requiring early aggressive intervention. Total number of pregnancies has declined over past decade, but the chances of ectopic pregnancies have increased, the incidence being maximum at the age of 25-30 years of age group. Nearly $95 \%$ of ectopic pregnancies occur in fallopian tubes, majority occur in the ampullary or isthmic portions of the fallopian tubes. About 2-3\% occurs as interstitial ectopic pregnancies (arising in the part of the tube which goes through the endometrial cavity). Other sites are cervical, fimbrial, ovarian and peritoneal sites, as well as previous caesarean section scars. ${ }^{1}$ Pain is the commonest symptom followed by vaginal bleeding and history of amenorrhea (triad of ectopic pregnancy) but the signs and symptoms vary 
depending on the fact whether the ectopic is ruptured or not. Most of the tubal pregnancies become symptomatic within 12 weeks, but a small number of them progress beyond this gestation and are diagnosed late. ${ }^{3}$ Woman may present with non-specific symptoms, may be unaware of pregnancy or even present with hemodynamic shock and hence diagnosis requires high index of suspicion of ectopic pregnancy in a women of fertile age group presenting to the clinician with complaints related to reproductive system. Past history of pelvic inflammatory disease, previous tubal surgery or ectopic pregnancy, progestin contraceptive, assisted reproduction, ovulation induction, induced abortion, salpingitis isthmica nodosa, smoking, and diethyl stilbestrol exposure are the risk factors for ectopic pregnancy. ${ }^{4,5}$ Likelihood of ectopic pregnancy also increases where there are multisexual partner, prior caesarean section and cigarette smoking at the time of conception. $^{6}$ The purpose of this study was to highlight the clinical presentation, presence of associated risk factors, commonest site and outcome of the women presenting with ectopic pregnancy in a rural tertiary care centre.

\section{METHODS}

This was a retrospective study done in a tertiary care rural medical teaching hospital in Mullana, Haryana, India.

\section{Inclusion criteria}

- All cases with the diagnosis of ectopic pregnancy who were managed in our hospital from August 2016 to September 2018.

\section{Exclusion criteria}

- Cases diagnosed with ectopic pregnancy who left the hospital without definitive treatment.

The medical records of women diagnosed with ectopic pregnancy in the said period were obtained from the medical record section of the hospital. Women's characteristics like age, place of residence, booking status, marital status, parity, and presence of any risk factors were noted. Details of clinical presentation, obstetrical, medical and surgical history and any history of pelvic infection, infertility, previous ectopic pregnancy, caesarian section or abortion were documented. Findings of general, abdominal and gynaecological examination were noted. Mode of diagnosis, type of treatment given, need of blood transfusion, site and type of ectopic pregnancy, histopathological diagnosis of the specimen obtained, and outcome of the women were recorded.

\section{Statistical analysis}

All data collected was entered in Microsoft Office Excel sheet version 2007 and analyzed using SPSS software version 21. Numerical data was subjected to descriptive analysis with mean \pm standard deviation (SD) whereas categorical data was analyzed as frequencies and percentages.

\section{RESULTS}

All women in present study were unbooked, nonsmokers, married and belonged to rural areas of Haryana and UP. Eighty percent (32) of them were in the age group of 20 to 30 years with the mean age of $27.85 \pm 3.75$ years. Maximum number of women was either gravida 3 or 4. Commonest presenting symptom was abdominal or pelvic pain followed by amenorrhoea. Triad of pain, vaginal bleeding and amenorrhoea was seen in 18 (45\%) women.

Table 1: Patient characteristics.

\begin{tabular}{|c|c|c|}
\hline Characteristics & $\mathrm{n}=40$ & $\%$ \\
\hline \multicolumn{3}{|c|}{ Age $($ Mean $=27.85 \pm 3.75 ; 22-38$ years $)$} \\
\hline $20-25$ years & 14 & 35 \\
\hline $25-30$ years & 18 & 45 \\
\hline $30-35$ years & 7 & 17.5 \\
\hline $35-40$ years & 1 & 2.5 \\
\hline \multicolumn{3}{|l|}{ Gravida } \\
\hline 1 & 5 & 12.5 \\
\hline 2 & 4 & 10 \\
\hline 3 & 12 & 30 \\
\hline 4 & 13 & 32.5 \\
\hline 5 & 2 & 5 \\
\hline 6 & 3 & 7.5 \\
\hline 7 & 1 & 2.5 \\
\hline \multicolumn{3}{|l|}{ Gestational age } \\
\hline$<4$ weeks & 4 & 10 \\
\hline 4-6 weeks & 9 & 22.5 \\
\hline 6-8 weeks & 19 & 47.5 \\
\hline $8-10$ weeks & 4 & 10 \\
\hline 10-12 weeks & 3 & 7.5 \\
\hline$>12$ weeks & 1 & 2.5 \\
\hline \multicolumn{3}{|l|}{ Symptoms } \\
\hline Abdominal pain & 38 & 95 \\
\hline Amenorrhoea & 36 & 90 \\
\hline Vaginal bleeding & 23 & 57.5 \\
\hline Triad & 18 & 45 \\
\hline \multicolumn{3}{|l|}{ Signs } \\
\hline Shock & 15 & 37.5 \\
\hline Abdominal tenderness & 22 & 55 \\
\hline Cervical tenderness & 23 & 57.5 \\
\hline Adenaxal mass & 6 & 15 \\
\hline \multicolumn{3}{|l|}{ Haemoglobin } \\
\hline$<7 \mathrm{gm} \%$ & 7 & 17.5 \\
\hline $7-9 \mathrm{gm} \%$ & 27 & 67.5 \\
\hline $9-11 \mathrm{gm} \%$ & 4 & 10 \\
\hline$>11 \mathrm{gm} \%$ & 2 & 5 \\
\hline
\end{tabular}

Fifteen $(37.5 \%)$ females were in shock on presentation in the emergency department. Abdominal tenderness was present in $22(55 \%)$ women whereas cervical tenderness 
was elicited in $23(57.5 \%)$ women. Nineteen $(47.5 \%)$ women presented with gestational age of 6 to 8 weeks (Table 1). Commonest risk factors (Table 2) observed were history of previous abortion in $19(47.5 \%)$ followed by PID in $8(20 \%)$ women, previous LSCS in $7(17.5 \%)$, history of infertility in $4(10 \%)$, past / family history of tuberculosis in $4(10 \%)$ and previous ectopic pregnancy in $3(7.5 \%)$ women.

Multiple risk factors were noted. Urine for pregnancy test was positive in all the women. Utrasonography was done in all the women.

Table 2 Risk factors.

\begin{tabular}{|l|l|l|}
\hline Risk factors & N=40 & \% \\
\hline Previous abortion & 19 & 47.5 \\
\hline Previous LSCS & 7 & 17.5 \\
\hline Previous ectopic & 3 & 7.5 \\
\hline History of infertility & 4 & 10 \\
\hline History of appendectomy & 1 & 2.5 \\
\hline History of PID / RTI & 8 & 20 \\
\hline Past / family history of TB & 4 & 10 \\
\hline
\end{tabular}

Eighty five percent (34) of the women had moderate to severe anaemia. Commonest site of ectopic pregnancy was tubal seen in $34(85 \%)$ women and non-tubal sites included ovarian 2, interstitial 2, cervical 1 and caesarean scar pregnancy in $1(2.5 \%)$ (Table 3$)$.

Table 3 Type and site of ectopic.

\begin{tabular}{|l|l|l|}
\hline Type & $\mathbf{N = 4 0}$ & $\%$ \\
\hline Ruptured & 36 & 9087.5 \\
\hline Unrupturred & 4 & 10 \\
\hline Site & & \\
\hline Tubal & 34 & 85 \\
\hline $\begin{array}{l}\text { Others (cervical 1, ovarian 2, cesarean } \\
\text { scar ectopic 1, interstitial 2) }\end{array}$ & 6 & 15 \\
\hline
\end{tabular}

Out of 40 women, $36(90 \%)$ had ruptured ectopic (tubal 32, interstitial 2 (Figure 1), ovarian 1 (Figure 2) and caesarean scar rupture 1) and unruptured ectopic included tubal 2 (Figure 3), cervical 1 and ovarian one.

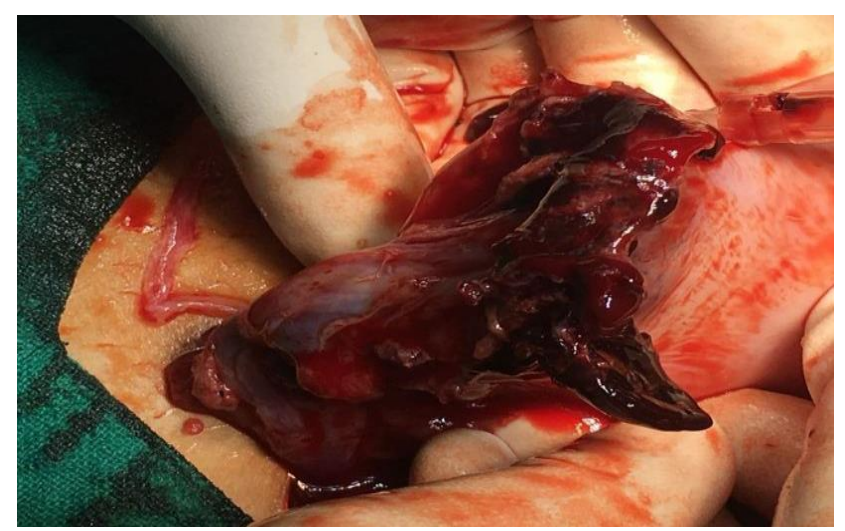

Figure 1 Ruptured right interstitial pregnancy

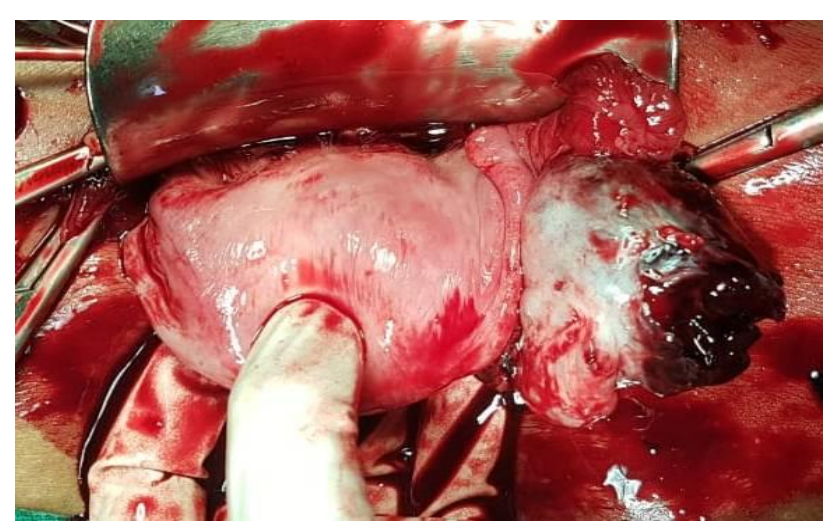

Figure 2: Ruptured right ovarian pregnancy.

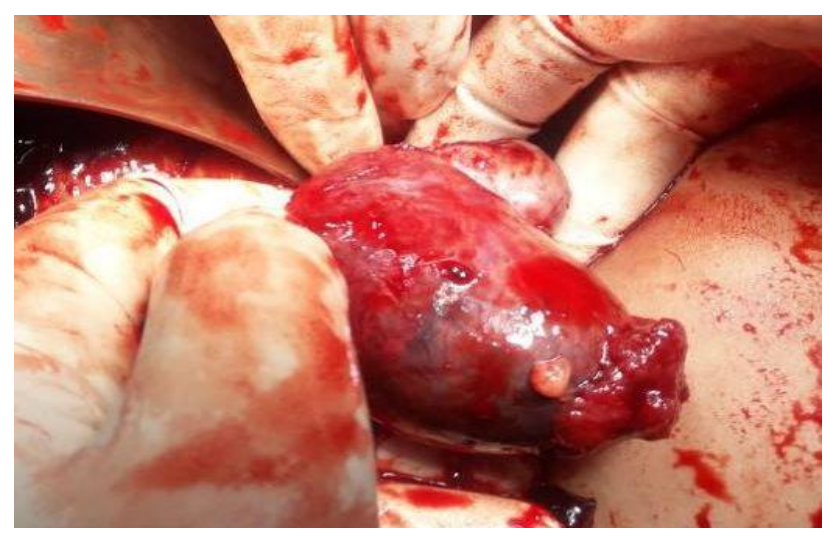

Figure 3: Unruptured right tubal pregnancy

Surgical management (Table 4) was done in 39 women whereas only one female fulfilled the criteria for medical management. Laparotomy was done in $95 \%$ of women and one underwent laparoscopic removal of the affected tube. Salpingectomy was the commonest surgical procedure done in $32(80 \%)$ women for ruptured tubal ectopic pregnancy.

Table 4: Surgical management.

\begin{tabular}{|l|l|l|}
\hline Medical (1) & & $\%$ \\
\hline $\begin{array}{l}\text { Surgical (39) } \\
\text { Laparoscopy (1) }\end{array}$ & Salpingectomy Rt & 2.5 \\
\hline Laparotomy (38) & & 2.5 \\
\hline & $\begin{array}{l}\text { Salpingectomy 32 } \\
\text { Salpingo ophrectomy 1 }\end{array}$ & 80 \\
\hline & Hysterectomy 2 & 2.5 \\
\hline & $\begin{array}{l}\text { Cornual resection 1 } \\
\text { Partial ovarectomy 1 }\end{array}$ & 2.5 \\
\hline & $\begin{array}{l}\text { Evacuation and repair of } \\
\text { uterine defect in scar ectopic 1 }\end{array}$ & 2.5 \\
\hline
\end{tabular}

Salpingo ophrectomy was done in one woman for ruptured ovarian pregnancy. Lifesaving hysterectomy was required in $2(5 \%)$ women for cervical and ruptured interstitial ectopic pregnancy one each. Partial overectomy and cornual resection was done in one case 
each. One woman with previous scar underwent evacuation and repair of the uterine rent. Out of 34 tubal ectopic pregnancies, right tube was involved in 21 $(52.5 \%)$ women. The commonest site of tube involved was ampulla $(24,70.6 \%)$. Blood transfusion was required in $28(70 \%)$ women. Surgical specimens were sent for histopathology which confirmed the diagnosis. No mortality was seen in the present study.

\section{DISCUSSION}

Commonest age of ectopic pregnancy presentation in present study was 20 to 30 years which is same as reported by other authors., ${ }^{7,8}$ Maximum numbers of women were either gravida 3 or 4 . Commonest presenting symptom was abdominal or pelvic pain followed by amenorrhoea. The classical triad of abdominal pain, amenorrhoea and vaginal bleeding was seen in $45 \%$ of our cases and is similar to the observations of $\mathrm{S}$ Tahmina et al whereas others have reported it to be present in wide range from $28-95 \%$ which indicates that the triad may not be a presenting feature in all the women coming with ectopic pregnancy. ${ }^{7,9,10,11}$ In present study, history of amenorrhoea was seen in $90 \%$ of females, but this may not be the presenting complaint unless specially asked for it. We observed that fifteen $(37.5 \%)$ women presented with shock which required immediate resuscitation, surgical intervention, blood transfusion and admission to the ICU. All these women were referred to us late when the ectopic had ruptured and haemorrhage was severe enough to produce shock.

Multiple risk factors for ectopic pregnancy were observed by us but history of previous abortion (47.5\%) was the commonest amongst all and is same as reported others. ${ }^{9,11,12,13,14,15,16}$ History of Pelvic Inflammatory Disease (PID) was seen in $20 \%$ of our women which is similar to that observed by Singh et al., and Mufti et al Urine for pregnancy test and utrasonography are noninvasive and economical tests recommended to aid the diagnosis of ectopic pregnancy and these were positive in most of our women. ${ }^{7,9,12}$ Blood loss and pain due to ruptured ectopic pregnancy results in anaemia, hypovolemic and neurogenic shock and requires immediate surgical intervention along with blood transfusions.

Laparotomy was done in $95 \%$ of our women and salpingectomy was the most common intervention done. A high rate of surgical management of the ectopic pregnancy has also been reported by many authors in the past. ${ }^{7,13,14,15,17}$ Commonest site of ectopic pregnancy seen by us was tubal in 34 (85\%) women which is comparable to findings of Tahmina et al Blood transfusion was required in $28(70 \%)$ women implying the necessity of efficient coordination with the blood bank of the hospital for urgent requirement of blood. ${ }^{7}$ No mortality was seen in the present study indicating that prompt diagnosis and treatment of the young fertile women coming with ectopic pregnancy can save their lives.

\section{CONCLUSION}

We conclude that any women in reproductive age group coming to the hospital with history of pain abdomen and menstrual complaints or irregularities, even without history of amenorrhoea, ectopic pregnancy should be ruled out by doing on the spot urine pregnancy test and an ultrasound. If diagnosis of ectopic pregnancy is made, early intervention will decrease the maternal morbidity and mortality. Treating reproductive tract infections / PID and offering contraception methods will ultimately decrease the incidence of ectopic pregnancy. Medical and paramedical staff working in the peripheral settings should be aware of the risk factors, sign and symptoms of ectopic pregnancy so that timely referral to the higher centres can be made.

Funding: No funding sources

Conflict of interest: None declared

Ethical approval: Not required

\section{REFERENCES}

1. Cunningham FG, Leveno KJ, Bloom SL, Spong CY, Dashe JS, Hoffman BL, . Ectopic Pregnancy. In:. Williams obstetrics $24^{\text {th }}$ ed. New York, NY: McGraw- Hill Medical;2014:377-395.

2. Barash JH, Buchanan EM, Hillson C. Diagnosis and management of ectopic pregnancy. Am Fam Physician. 2014;90(1):34-40.

3. Tasnim N, Mahmud G. Advance abdominal pregnancy-a diagnostic and management dilemma. J Coll Physicians Surg Pak. 2005;15(8):493-5.

4. Shah N, Khan NH. Ectopic pregnancy: Presentation and risk factors. J Coll Physicians Surg Pak. 2005;15(9):535-8.

5. Basu A, Candelier C. Ectopic pregnancy with postcoital contraception-a case report. Eur J Contracept Reprod Health Care. 2005;10(1):6-8.

6. Barnhart KT, Sammel MD, Gracia CR, Chittams J, Hummel AC, Shaunik A. Risk factors for ectopic pregnancy in women with symptomatic firsttrimester pregnancies. Fertil Steril. 2006;86(1):3643.

7. Tahmina S, Mary Daniel, Preethy Solomon. Clinical Analysis of Ectopic Pregnancies in a Tertiary Care Centre in Southern India: A Six-Year Retrospective Study. J Clinic Diagnos Res. 2016;10(10):13-16.

8. Aqueela Ayaz, Sameh Emam, and Mian Usman Farooq. Clinical course of ectopic pregnancy: A single-center experience. J Hum Reprod Sci. 2013;6(1):70-3.

9. Singh S, Mahendra G, Vijayalakshmi S, Pukale RS. Clinical study of ectopic pregnancy in a rural setup: A two-year survey. Natl J Med Res. 2014;4(1):37-9. 
10. Jabbar FA, Al-Wakeel M. A study of 45 cases of ectopic pregnancy. Int J Gynaecol Obstet Off Organ Int Fed Gynaecol Obstet. 1980;18(3):214-17.

11. Jani R, Munshi D, Jani S, Munshi S. Study of 50 cases of modern management of ectopic pregnancy. Int J Reprod Contracept Obstet Gynecol. 2014;3(2):374-79.

12. Mufti S, Rather S, Mufti S, Rangrez RA, Wasiqa K. Ectopic pregnancy: An analysis of 114 cases. JKPract. 2012;17(4):20-3.

13. Udigwe GO, Umeononihu OS, Mbachu II. Ectopic pregnancy: a 5-year review of cases at nnamdiazikiwe university teaching hospital (NAUTH) Nnewi. Niger Med J. 2010;51(4):160.

14. Igwegbe A, Eleje G, Okpala B. An appraisal of the management of ectopic pregnancy in a Nigerian tertiary hospital. Ann Med Health Sci Res. 2013;3(2):166-70.

15. Shetty S, Shetty A. A clinical Study of Ectopic Pregnancies in a Tertiary care hospital of Mangalore, India. Innov J Med Health Sci. 2014;4(1).
16. Shobeiri F, Tehranian N, Nazari M. Trend of ectopic pregnancy and its main determinants in Hamadan province, Iran (2000-2010). BMC research notes. 2014;7(1):733.

17. Cornelius AC, Onyegbule A, Onyema null, Uchenna ET, Duke OA. A five-year review of ectopic pregnancy at Federal Medical Centre, Owerri, South East, Nigeria. Niger J Med J Natl Assoc Resid Dr Niger. 2014;23(3):207-12.

Cite this article as: Verma I, Priya $\mathrm{P}$, Chugh $\mathrm{C}$, Kaur H, Sood D. Clinical presentation and outcome of ectopic pregnancies in a tertiary care rural hospital. Int J Reprod Contracept Obstet Gynecol 2019;8:692-6. 